\title{
Understanding Conformational Preferences of Atropisomeric Hydrazides and Its Influence on Excited State Transformations in Crystalline Media
}

\author{
Akila Iyer ${ }^{1}$, Angel Ugrinov ${ }^{2}$ and J. Sivaguru ${ }^{1, *}$ \\ 1 Center for Photochemical Sciences and Department of Chemistry, Bowling Green State University, \\ Bowling Green, $\mathrm{OH} 43403$, USA \\ 2 Department of Chemistry and Biochemistry, North Dakota State University, Fargo, ND 58108-6050, USA \\ * Correspondence: sivagj@bgsu.edu; Tel.: +1-419-372-9450; Fax: +1-419-372-1843
}

Academic Editor: Linda S. Shimizu

Received: 15 July 2019; Accepted: 5 August 2019; Published: 19 August 2019

Abstract: Hydrazides derivatives were evaluated to understand the role of $N-N$ bond in dictating the outcome of photoreactions in the solid state.

Keywords: atropselective photoreactions; photochirogenesis; asymmetric photochemistry; chiral photochemistry; photochiral auxiliary; hydrazide based photochromophores

\section{Introduction}

Nature employs light as a powerful reagent to perform chemical transformations for many life-sustaining processes. Scientists have tried to mimic the processes in nature to design and develop methodologies for the synthesis of complex structural scaffolds and for building photoresponsive materials and molecular assemblies with unique architectures [1,2]. One of the critical aspects to control chemical transformations from the excited state involves harnessing the reactivity and dynamics of photoexcited species. Supramolecular assemblies, in particular crystalline media, have potential to channel the reactivity of the excited states towards useful chemical pathways [3]. Recently, research from our group established the use of hydrazides as effective photoauxiliary for carrying out various excited state transformations $[4,5]$. In this report, we have evaluated the role of hydrazides as photoactive units in crystalline media. Gilchrist and coworkers reported the photochemistry of hydrazides [6] in which 1-phthalimidoaziridine underwent photoaddition with alkenes to yield the corresponding aziridine skeleton. The proof of concerted fragmentation of the phthalimidoaziridines to give olefin and corresponding phthalimidonitrene was confirmed by trapping the nitrene. Couture and coworkers $[7,8]$ reported an efficient strategy that utilizes non-oxidative, photoinduced $N-N$ bond cleavage. Watterson and coworkers [9] reported that irradiation of acyclic hydrazides resulted in $\mathrm{N}-\mathrm{C}(\mathrm{CO})$ (carbonyl) and $\mathrm{N}-\mathrm{N}$ bond cleaved products. Based on literature precedence, our group has developed hydrazides as a photochiral auxiliary to carry out excited state transformations [4,5]. In this report, we present our results on the influence of $N-N$ bond in controlling the excited state reactivity of compounds $\mathbf{1}$ and 2a-d in the solid state (Scheme 1).<smiles>C=C(C)C(=O)N(C(=O)C(=C)C)N1C(=O)c2ccccc2C1=O</smiles>

1

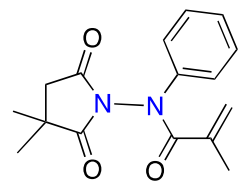

$2 a$

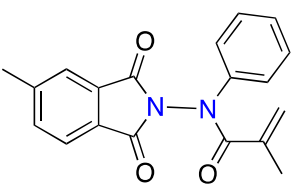

2b

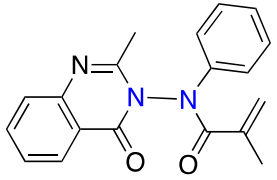

$2 c$

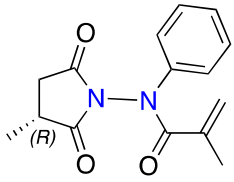

2d

Scheme 1. Hydrazides with restricted $N-N$ bond rotation evaluated towards solid state photoreaction. 


\section{Results and Discussion}

An important and unique feature shown by hydrazides in crystalline media relates to the pyramidalization of the nitrogen atom [10-22]. There have been few reports in the literature on the single crystal XRD analysis of $N-N$ bond based compounds that shed light on this unusual feature and describe such hydrazides as atypical compounds. Aitken and coworkers attribute the $N-N$ bond twist in $N$-Acetylamino phthalimide to intermolecular H-bonding interactions [22]. They observed an unusually large torsional angle $\theta(\mathrm{CO}-\mathrm{N}-\mathrm{N}-\mathrm{CO})$ of $\sim 86^{\circ}$ that explains the orthogonality between the two planes containing each nitrogen atom. As we were successful in obtaining good quality crystals for single crystal XRD analysis of hydrazides 1 and 2 (Figure 1), we became interested to understand the conformational features and how they impacted reactivity in the excited state [23]. The torsional angles $\theta(\mathrm{CO}-N-N-\mathrm{CO})$ for $\mathbf{1}, \mathbf{2 a}, \mathbf{2 b}$, and $2 \mathrm{c}$ was $\sim 76.9^{\circ}, \sim 72.4^{\circ}, \sim 72.8^{\circ}$, and $\sim 82.8^{\circ}$, respectively (Figure 1; Table 1). For quinazolinone based hydrazide $2 \mathrm{c}$ the measured torsional angles $\theta$ being $\sim 82.8^{\circ}$ confirmed the planes of the groups on the two nitrogen atoms to be nearly perpendicular. This is expected from the repulsive interactions between the lone pair on the two heteroatoms.

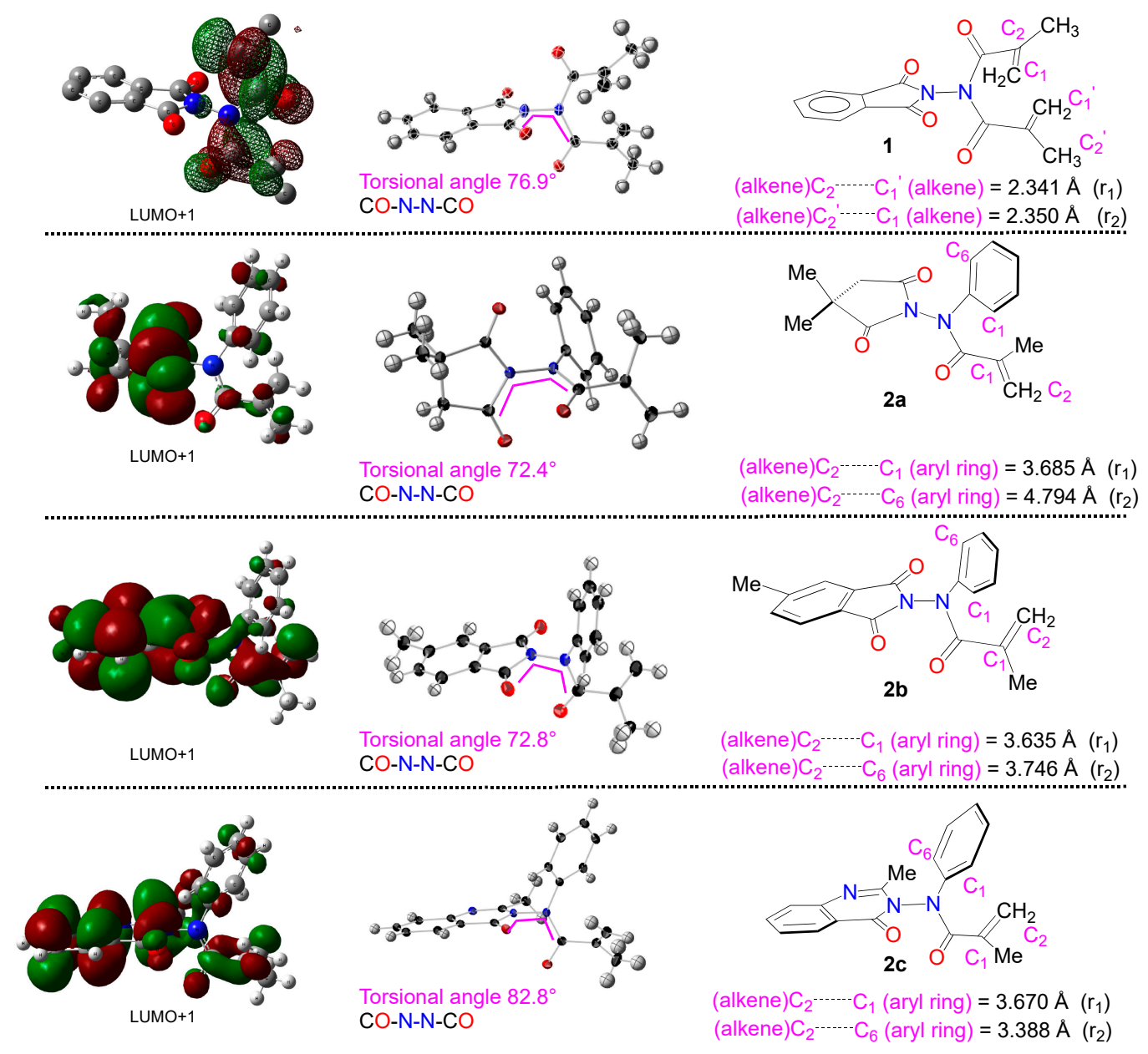

Figure 1. Understanding the solid state photochemical reactivity based on orbital density computed with Gaussian 09 at B3LYP/6-31G* and single crystal XRD analysis of hydrazides $\mathbf{1}, \mathbf{2 a}, \mathbf{2 b}$, and $\mathbf{2 c}$. 
Table 1. Torsional angle $(\theta)(\mathrm{CO}-N-N-\mathrm{CO})$ of the evaluated hydrazides ${ }^{\mathrm{a}}$.

\begin{tabular}{ccc}
\hline Entry & Hydrazide & Torsional Angle $(\theta)$ \\
\hline 1 & $\mathbf{1}$ & $76.9^{\circ}$ \\
2 & 2a & $72.4^{\circ}$ \\
3 & 2b & $72.8^{\circ}$ \\
4 & 2c & $82.8^{\circ}$
\end{tabular}

a Torsional angle $(\theta)$ were measured from single crystal XRD analysis of hydrazides.

As monoacylated nitrogen on hydrazides exhibit axial chirality $\left(\Delta G^{\ddagger}\right.$ rac $\sim 23 \mathrm{kcal} / \mathrm{mol}$, $T_{\mathrm{c}}=188^{\circ} \mathrm{C}$ ) $[15,24]$, we evaluated hydrazides $\mathbf{2 a - c}$ as they have asymmetrical substitution around the $N-N$ bond. HPLC analysis of hydrazides (Figure 2) using chiral stationary phase showed partial separation of enantiomers for $\mathbf{2} \mathbf{a}$ and $\mathbf{2} \mathbf{b}$ indicating that the $N-N$ bond rotation at room temperature is not favorable for resolution of the enantiomers. Verma and coworkers have extensively documented studies $[14,15,25]$ on restricted $N-N$ bond rotation in camphorimide/other dimidyl based hydrazides and have mentioned moderate to high rotational barrier by NMR spectral analysis [26-33]. In case of succinimide 2a, peak shape characteristics reflected two resolved peaks albeit with fast rotation around the $\mathrm{N}-\mathrm{N}$ bond under our separation conditions $[34,35]$. We then synthesized chiral phthalimide-derived hydrazide $\mathbf{2} \mathbf{b}$ and the HPLC separation did not show any base-to-base separation at room temperature (Figure 2). The 5,6-fused aromatic ring system in phthalimide $\mathbf{2} \mathbf{b}$ was then altered to a 6,6-fused aromatic ring system of quinazolinone-based acrylanilide $2 \mathrm{c}$ as quinazolinone diacylated hydrazides have been shown to yield stable atropisomers [18,20,21,36-41].

Based on chiral stationary phase based HPLC analysis, the quinazolinone derived hydrazide $2 \mathrm{c}$ showed well-resolved peaks for the individual $P$ and $M$ atropisomers (Figure 2). Table 2 reveals the kinetic parameters for single bond rotation for $2 \mathrm{c}$ where appreciable barrier for $N-N$ bond rotation was observed. The barrier for racemization $\left(\Delta G^{\ddagger}\right.$ rac $)$ in ethyl acetate (polar solvent) was found to be $\sim 24.2 \mathrm{kcal} / \mathrm{mol}$ at $45^{\circ} \mathrm{C}$ with a racemization rate constant $\left(k_{\mathrm{rac}}\right)$ of $16.4 \times 10^{-5} \mathrm{~s}^{-1}$ that corresponded to a half-life of racemization $\left(\tau_{1 / 2}\right)$ of $1.2 \mathrm{~h}$. Changing the solvent from ethyl acetate to benzene (non-polar solvent) had a minor influence on the racemization kinetic parameters. The activation barrier for racemization $\left(\Delta G^{\ddagger}\right.$ rac $)$ at $45{ }^{\circ} \mathrm{C}$ was found to be $\sim 23.9 \mathrm{kcal} / \mathrm{mol}$ with a racemization rate constant $\left(k_{\mathrm{rac}}\right)$ of $2.15 \times 10^{-4} \mathrm{~s}^{-1}$ that corresponded to a half-life of racemization $\left(\tau_{1 / 2}\right)$ of $0.89 \mathrm{~h}$. This suggests that the $\mathrm{N}-\mathrm{N}$ bond based optically pure atropisomers could be stable atropisomers at room temperature.

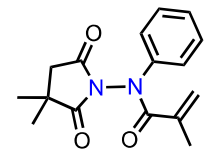

2a

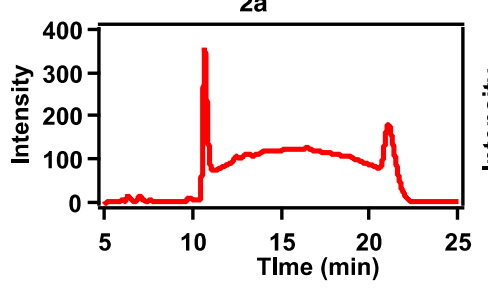

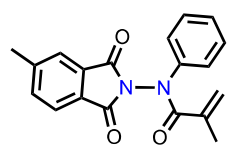

2b

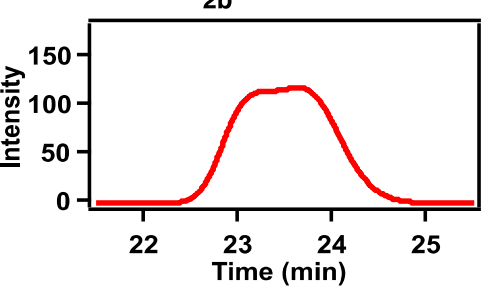

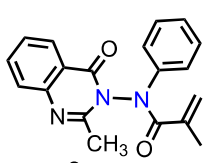

2c

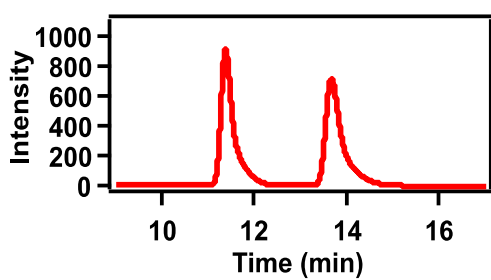

Figure 2. HPLC analysis of hydrazides $\mathbf{2 a - c}$ on a chiral stationary phase. HPLC condition: Figure 2. CHIRALPAK ${ }^{\circledR}$ IC, mobile phase hexane:2-propanol 70:30, flow rate: $1.0 \mathrm{~mL} / \mathrm{min}$, retention times $10.6 \mathrm{~min}$ and $20.9 \mathrm{~min}$; 2b CHIRALPAK ${ }^{\circledR}$ IC, mobile phase-hexane:2-propanol 70:30, flow rate: $0.8 \mathrm{~mL} / \mathrm{min}$, HPLC condition; broad peak from 22.4-25.0 min; 2c CHIRALPAK ${ }^{\circledR}$ AD-H, mobile phase hexane:2-propanol 70:30, flow rate: $0.8 \mathrm{~mL} / \mathrm{min}$, retention times $11.4 \mathrm{~min}$ and $13.7 \mathrm{~min}$. 
Table 2. Kinetic parameters of racemization barrier for hydrazide $2 c^{a}$.

\begin{tabular}{|c|c|c|c|c|}
\hline \multirow{2}{*}{ Entry } & \multirow{2}{*}{ Solvent } & \multicolumn{3}{|c|}{ Kinetic Parameters } \\
\hline & & $\tau_{1 / 2}(h)$ & $k_{r a c}\left(\mathrm{~s}^{-1}\right)$ & $\Delta G^{\ddagger}{ }_{r a c}\left(\mathrm{kcal} \mathrm{mol}^{-1}\right)$ \\
\hline 1 & Benzene & 0.89 & $2.15 \times 10^{-4}$ & 23.9 \\
\hline 2 & Ethyl acetate & 1.20 & $16.4 \times 10^{-5}$ & 24.2 \\
\hline
\end{tabular}

a Values carry an error of $\pm 5 \%$. The racemization kinetics was followed at $45^{\circ} \mathrm{C}$ by HPLC analysis on a chiral stationary phase.

Having established the importance of axial chirality centered around $N-N$ bond, we evaluated hydrazide $\mathbf{1}$ for [2+2] photocycloaddition and hydrazides $\mathbf{2 a - c}$ towards $6 \pi$-photocyclization, to understand the effect of conformational preferences in crystalline media and their impact on the excited state reactivity. The photoreactions were performed under the conditions of direct irradiation by exposing the crystals to appropriate wavelength of light. The acrylimide based hydrazide 1 underwent solid state [2+2] photoreaction to afford corresponding cycloadduct 3 (Scheme 2). The photoproduct was characterized by ${ }^{1} \mathrm{H}-\mathrm{NMR}$ spectroscopy. While [2+2]-photocycloaddition of hydrazide in the solid state occurred as expected, the $6 \pi$-photocyclization of hydrazides showed some interesting trends. Hydrazides $\mathbf{2 b}$ and $\mathbf{2 c}$ on irradiation underwent $6 \pi$-photocyclization in solid state to the corresponding cyclized product $4 \mathbf{b}$ and $4 c$, respectively. However, the hydrazide $2 a$ on subjecting to two different light sources viz $\lambda \sim 300 \mathrm{~nm}$ and $\lambda \sim 254 \mathrm{~nm}$ did not afford the corresponding cyclized product. The crystals were stable and no decomposition was observed. The stability of the crystal was monitored until $72 \mathrm{~h}$ by single crystal XRD. We postulate the bond distances/the conformation make-up of the hydrazide in the crystalline lattice to be the plausible reason that explains the ability/inability of these substrate to undergo solid state photoreaction. To gain better understanding we performed DFT calculations at B3LYP/6-31G* level of theory using the cartesians obtained from single crystal XRD structures. The LUMO+1 states for succinimide based acrylanilide $\mathbf{2 a}$ showed negligible orbital localization on the $C_{2}$ carbon $\left(C_{1}=C_{2}\right)$ of methacryloyl functionality when compared to other hydrazides (Figure 1 ). An appreciable orbital density was observed on the terminal alkenyl carbon for the hydrazides that underwent photoreaction in solid state.

\section{[2+2]-Cross photocycloaddition}<smiles>C=C(C)C(=O)N(C(=O)C(=C)C)N1C(=O)c2ccccc2C1=O</smiles><smiles>CCCCCCC1CCCCC1</smiles><smiles>C[C@@]12CC[C@](C)(C1=O)N(N1C(=O)c3ccccc3C1=O)C2=O</smiles>

$6 \pi$-Photocyclization<smiles>C=C(C)C(=O)N(c1ccccc1)N1CCCCCC1=O</smiles>

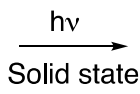

2a-c<smiles>CC1Cc2ccccc2N(N2CCCCCC2=O)C1=O</smiles>

4a-c<smiles>C=C(C)C(=O)N(c1ccccc1)N1C(=O)C[C@H](I)C1=O</smiles><smiles>CC(C)[C@@H]1CC(=O)N(N2C(=O)[C@H](C)Cc3ccccc32)C1=O</smiles>

Scheme 2. Photoreactivity of hydrazides in the solid state.

A closer examination of single crystal XRD structure suggests that only in the case of succinimide based hydrazide $\mathbf{2 a}$, the terminal alkene carbon points away from the phenyl group. Further the measured bond distances from the single crystal XRD structures for the distances between C1/C6 carbon atom(s) of the phenyl ring to the terminal alkenyl carbon for $\mathbf{2 b}$ and $\mathbf{2 c}$ were both within the Schmidt distance (for $\mathbf{2 b} \mathrm{r} 1=3.635 \AA$ and $\mathrm{r} 2=3.746 \AA$; for $\mathbf{2} \mathbf{c} \mathbf{r} 1=3.670 \AA$ and $\mathrm{r} 2=3.388 \AA$ ). However, for hydrazide $2 \mathrm{a}$ the measured bond distance was slightly larger than the optimal distance for $\mathrm{C} 6$ (phenyl)-C2 $\left(\mathrm{C}_{1}=\mathrm{C}_{2}\right)$ bond $(\mathrm{r} 1=3.685 \AA$ and $\mathrm{r} 2=4.794 \AA$ ). 
To bias the restricted bond rotation towards one atropisomer, $(R)$-methyl succinimide based hydrazide 2d (Scheme 2; Figure 3) with a point chiral center was evaluated both in solution and in the solid state. The presence of the chiral center, forced crystallization of the $(R, M)$-isomer of $\mathbf{2 d}$ leading to optical resolution of the diastereomers. Inspection of the crystal structures showed four molecules per unit cell (Figure 3, structure A, B, C and D) with both s-cis (Figure 3A,D) and s-trans (Figure 3B,C) OC-C rotamer in the same unit cell. The structural overlay (Figure 3 right) indicates that the $N$-phenyl ring exhibits different orientation within the individual rotamers. As the cyclization distance was optimal in the solid state, irradiation of the crystals of $(R, M)-\mathbf{2 d}$ resulted in the photocyclized product $\mathbf{4 d}$ (Scheme 2). Slow rotation of $N-N$ bond leading to diasteromerization was observed during the HPLC analysis of the photoproduct $4 \mathbf{d}$. Nevertheless, the results clearly showcase the ability of restricted bond rotation around $N-N$ bond and crystalline confinement can lead to good stereoenrichment in the photoproduct.
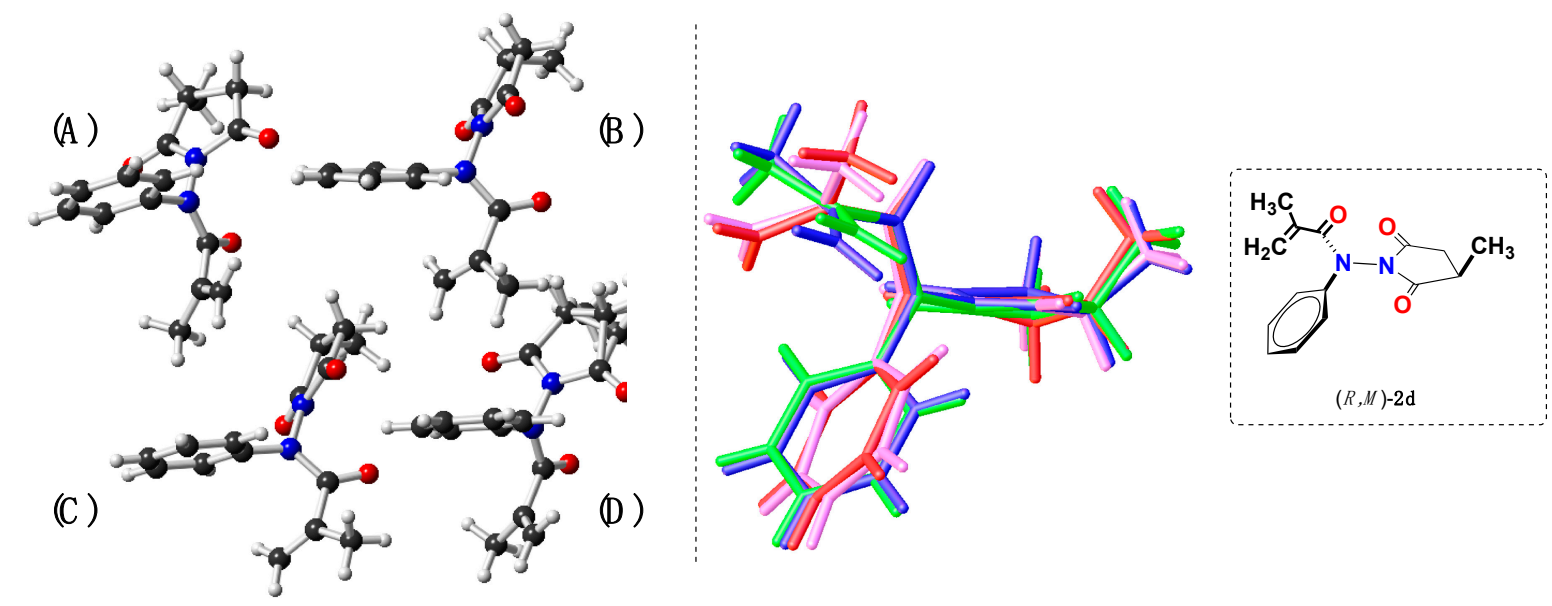

Figure 3. Single crystal XRD analysis performed for $(R)$-methyl succinimide based hydrazide $\mathbf{2 d}$. A-D represents (R,M)-2d in a unit cell. The CCDC Deposition Number 1943951. (Refer to supporting information).

\section{Conclusions}

Our study clearly demonstrates the power of $N-N$ bond to enforce reactivity in the crystalline state. The conformational aspects of the hydrazides in the present study corroborates with literature precedence. The orthogonality of the planes containing the two nitrogen centers provides a useful handle to control the stereochemistry of photoreactions in the solid state. The research lays down the path for developing chirality around $N-N$ bond in hydrazides and channels its excited state energy to afford synthetically useful scaffolds in crystalline media.

\section{Materials and Methods}

The synthesis and characterization of hydrazides $\mathbf{1}$ and $\mathbf{2} \mathbf{a}-\mathbf{c}$ as well as their corresponding photoproducts are reported in our previous communications [4,5,23]. All commercially obtained reagents/solvents were used as received; chemicals that were purchased from Alfa Aesar ${ }^{\circledR}$ (Ward Hill, MA, USA) Sigma-Aldrich ${ }^{\circledR}$ (St. Louis, MO, USA), Acros ${ }^{\circledR}$ (Geel, Belgium), TCI $^{\circledR}$ America (Portland, OR, USA), Mallinckrodt ${ }^{\circledR}$ (Petten, The Netherlands), and Oakwood Products ${ }^{\circledR}$ (West Columbia, Anaheim, CA, USA) were used as received without further purification. ${ }^{1} \mathrm{H}-\mathrm{NMR}$ and ${ }^{13} \mathrm{C}-\mathrm{NMR}$ spectra were recorded on Varian $400 \mathrm{MHz}(100 \mathrm{MHz})$ and on $500 \mathrm{MHz}(125 \mathrm{MHz})$ spectrometers. HPLC analyses were performed on Waters ${ }^{\circledR}$ HPLC (Milford, MA, USA) equipped with 2525 pump or on Dionex ${ }^{\circledR}$ Ultimate 3000 HPLC (Thermo Fisher Scientific, Bremen, Germany or Thermo Fisher Scientific Inc., Sunnyvale, CA, USA). Waters ${ }^{\circledR} 2767$ sample manager was used for automated sample injection. Chromeleon 7.0 (Dionex Thermoline Fisher Scientific, Waltham, MA, USA) software 
was used for analyzing HPLC injections on Dionex ${ }^{\circledR}$ HPLC. The reactants and photoproducts were purified by flash chromatography using silica gel (by standard technique with solvents as indicated).

High-resolution mass spectrum data in Electrospray Ionization mode were recorded on a Bruker-Daltronics ${ }^{\circledR}$ BioTof mass spectrometer (Billerica, MA, USA) in positive (ESI+) ion mode. Single crystal X-ray diffraction data of the compounds 1, 2a-d were collected on a Bruker Apex Duo diffractometer with an Apex 2 CCD area detector at $\mathrm{T}=100 \mathrm{~K}$. ImSCu source radiation was used in all the cases and the structures were processed using Apex 2 v2010.9-1 software package (Bruker-AXS, Madison, WI, USA). Direct method was used to solve the structures after multi-scan absorption corrections.

Following the modified procedure reported by Kaminski et al., a suspension of $(R)-(+)-$ methyl-succinic acid ( $R$ )-7 (1 equiv) in water (10 mL per gram of acid), phenyl hydrazine (1 equiv) was added [42]. The mixture was heated in an oil bath at $180^{\circ} \mathrm{C}$ with simultaneous removal of water (Scheme 3). After $1 \mathrm{~h}$, the mixture was brought to room temperature and the crude was diluted with ethyl acetate and the organic layer was sequentially washed with $10 \% \mathrm{HCl},(2 \times 10 \mathrm{~mL})$, DI water $(2 \times 10 \mathrm{~mL})$, saturated $\mathrm{NaHCO}_{3}(2 \times 10 \mathrm{~mL})$, and finally with brine. The organic layer was dried over anhyd $\mathrm{Na}_{2} \mathrm{SO}_{4}$, filtered and the solvent was removed under reduced pressure to yield crude product. After concentrating the organic layer, the crude product was purified by combiflash using hexanes and ethyl acetate mixture to get the desired hydrazide $(R)-6$. TLC condition $-R_{f}=0.3(50 \%$ ethyl acetate:hexanes). Crystalline solid (Yield = 40\%). ${ }^{1} \mathrm{H}-\mathrm{NMR}\left(400 \mathrm{MHz}, \mathrm{CDCl}_{3}, \delta \mathrm{ppm}\right): 1.41(\mathrm{~d}, 3 \mathrm{H}$, J 7.2 Hz), $2.44\left(\mathrm{dd}, 1 \mathrm{H}, J_{1} 17.6 \mathrm{~Hz}, J_{2} 3.6 \mathrm{~Hz}\right), 2.95-3.07(\mathrm{~m}, 2 \mathrm{H}), 6.09(\mathrm{bs}, 1 \mathrm{H}), 6.76(\mathrm{~d}, 2 \mathrm{H}, J 8 \mathrm{~Hz})$, $6.97(\mathrm{t}, 1 \mathrm{H}, \mathrm{J} 7.6 \mathrm{~Hz})$, and 7.21-7.25 (m, 2H). ${ }^{13} \mathrm{C}-\mathrm{NMR}\left(100 \mathrm{MHz}, \mathrm{CDCl}_{3}, \delta \mathrm{ppm}\right): 17.2,34.3,34.9,114.9$, $123.0,129.6,145.3,174.1$, and 179.4 .

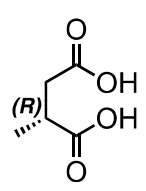

$(R)-7$

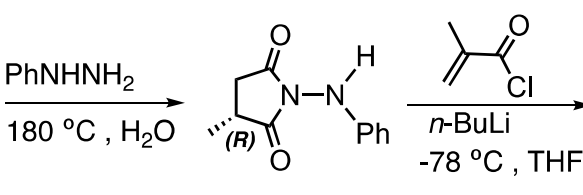

$(R)-6$

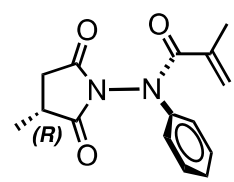

(R)-2d

Scheme 3. Synthesis of hydrazide derivative $(R)-2 d$.

Hydrazide derivative $(R)-6$ (1 equiv) was dissolved in anhydrous THF under an inert atmosphere. ${ }^{23}$ The solution was then cooled to $-78{ }^{\circ} \mathrm{C}$. To this cold solution $n$-BuLi $(2.5 \mathrm{M}, 1.1$ equiv) was added slowly. The mixture was stirred at this temperature for $1 \mathrm{~h}$. The reaction was quenched with anhydrous methacryloyl chloride (1.3 equiv). The stirring was continued for another $2 \mathrm{~h}$ after which the solution was quenched with slow addition of $\sim 10 \mathrm{~mL}$ of saturated $\mathrm{NH}_{4} \mathrm{Cl}$. (Note: The solution was quenched at $-78{ }^{\circ} \mathrm{C}$ ). The solution was further stirred for $35 \mathrm{~min}$ and then diluted with diethyl ether and the organic layer was sequentially washed with DI water $(2 \times 10 \mathrm{~mL})$, saturated $\mathrm{NaHCO}_{3}(2 \times 10 \mathrm{~mL})$, and finally with brine. The organic layer was dried over anhyd $\mathrm{Na}_{2} \mathrm{SO}_{4}$, filtered, and the solvent was removed under reduced pressure to yield crude product. After concentrating the organic layer, the crude product was purified by combiflash using hexanes and ethyl acetate mixture to get the desired compound. TLC condition- $-\mathrm{R}_{f}=0.6$ (50\% ethyl acetate:hexanes). Crystalline clear solid (Yield $=75 \%$ ). ${ }^{1} \mathrm{H}-\mathrm{NMR}\left(400 \mathrm{MHz}, \mathrm{CDCl}_{3}, \delta \mathrm{ppm}\right.$, rotamer peaks are reported together): $1.29(\mathrm{~d}, J 6.8 \mathrm{~Hz}), 1.39-1.43$ (m), $1.83(\mathrm{bs}), 2.28-2.45(\mathrm{~m}), 2.84-3.05(\mathrm{~m}), 5.19(\mathrm{~s}), 5.27(\mathrm{~m}), 7.29-7.35(\mathrm{~m})$, and 7.40-7.43 (m). ${ }^{13} \mathrm{C}-\mathrm{NMR}$ (100 MHz, $\mathrm{CDCl}_{3}, \delta \mathrm{ppm}$, rotamer peaks are reported together): 21.7, 22.0, 22.1, 38.4, 38.5, 39.9, 40.0, $41.9,131.6,132.7,132.9,133.8,133.9,133.9,134.3,134.5,134.6,177.5,177.7,181.6$, and 181.7. HRMS-ESI

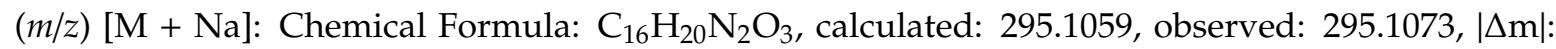
$4.7 \mathrm{ppm}$.

Condition for crystallization:

The hydrazide (5 mg) was added to a well-dried pyrex tube and then dissolved in an appropriate solvent (minimum volume). The solution was layered with another solvent (minimum volume) 
in which the hydrazide was insoluble. The vessel was then sealed with a rubber septum and a needle inserted on the septum to allow slow evaporation of the solvent. Solvent mixture used for crystallization for hydrazides: 1, 2a-d: Hexane/ethyl acetate. CCDC Deposition Number 1943951.

Supplementary Materials: The following are available: Single crystal XRD (CIF format), and characterization data. Single crystal X-ray data can be obtained from the supplementary materials ofor this paper. These data can also be obtained free of charge via http://www.ccdc.cam.ac.uk/conts/retrieving.html (or from the CCDC, 12 Union Road, Cambridge CB2 1EZ, UK; Fax: +44-1223-336033; E-mail: deposit@ccdc.cam.ac.uk) using CCDC Deposiotn number 1943951.

Author Contributions: All authors contributed to the research. Conceptualization, methodology, validation, and formal analysis, writing of the original draft was done by A.I. under the guidance of J.S. Supervision, project administration, and funding acquisition was done by J.S., A.U. solved the crystal structures.

Funding: This research was funded the generous support from the National Science Foundation (CHE-1811795).

Acknowledgments: This article is part of the supramolecular chemistry special issue.

Conflicts of Interest: The authors declare no conflict of interest.

\section{References}

1. De Jong, J.J.D.; Tiemersma-Wegman, T.D.; Van Esch, J.H.; Feringa, B.L. Dynamic Chiral Selection and Amplification Using Photoresponsive Organogelators. J. Am. Chem. Soc. 2005, 127, 13804-13805. [CrossRef] [PubMed]

2. Wei, J.J.; Schafmeister, C.; Bird, G.; Paul, A.; Naaman, R.; Waldeck, D.H. Molecular Chirality and Charge Transfer through Self-Assembled Scaffold Monolayers. J. Phys. Chem. B 2006, 110, 1301-1308. [CrossRef] [PubMed]

3. Ramamurthy, V.; Sivaguru, J. Supramolecular Photochemistry as a Potential Synthetic Tool: Photocycloaddition. Chem. Rev. 2016, 116, 9914-9993. [CrossRef] [PubMed]

4. Iyer, A.; Ahuja, S.; Jockusch, S.; Ugrinov, A.; Sivaguru, J. Conjugate addition from the excited state. Chem. Commun. 2018, 54, 11021-11024. [CrossRef] [PubMed]

5. Iyer, A.; Jockusch, S.; Sivaguru, J. A photo-auxiliary approach-enabling excited state classical phototransformations with metal free visible light irradiation. Chem. Commun. 2017, 53, 1692-1695. [CrossRef] [PubMed]

6. Rees, C.W.; Gilchrist, T.L.; Stanton, E. Reactives intermediates. XIV. Photochemistry of phthalimidoaziridines and related systems. J. Chem. Soc. C 1971, 988-993. [CrossRef]

7. Couture, A.; Lebrun, S.; Deniau, E.; Grandclaudon, P. Synthesis of Cyclic Enehydrazides by Ring-Closing Metathesis. Synthesis 2006, 2006, 3490-3494. [CrossRef]

8. Lebrun, S.; Couture, A.; Deniau, E.; Grandclaudon, P. A Practical Photochemically Induced Method for N-N Bond Cleavage of N,N-Disubstituted Hydrazides. Synlett 2009, 2009, 2621-2624.

9. Watterson, A.C.; Shama, S.A. Photochemistry of acid hydrazides. Determination of modes of reaction and identification of photoproducts. J. Org. Chem. 1975, 40, 19-24. [CrossRef]

10. Breliere, J.C.; Lehn, J.M. N.m.r. studies of rate processes and conformation. A double rate process. Chem. Commun. 1965, 426-427. [CrossRef]

11. King, G.S.D. The crystal and molecular structure of NN-prime or minute]-bisuccinimidyl. J. Chem. Soc. B Phys. Org. 1966, 1224-1229. [CrossRef]

12. Korsch, B.H.; Riggs, N.V. Restricted rotation about $N-N$ single bonds. The conformation of tetrahydropyridazine rings. Tetrahedron Lett. 1966, 7, 5897-5903. [CrossRef]

13. Price, B.; Sutherland, I.O.; Williamson, F.G. Conformational changes in diacyl-tetrahydropyridazine and piperidazine systems. Tetrahedron 1966, 22, 3477-3490. [CrossRef]

14. Bishop, G.J.; Price, B.J.; Sutherland, I.O. Torsional barriers in NN'-diacylhydrazines. Chem. Commun. 1967, 14, 672-674. [CrossRef]

15. Moriarty, R.M., Sr.; Murphy, M.R.; Druck, S.J.; May, L. Conformational studies on the amido group. Hindered internal rotation in N,N'-dialkyl hydrazocarboxylates. Tetrahedron Lett. 1967, 8, 1603-1609. [CrossRef]

16. Atkinson, R.S.; Judkins, B.D.; Patwardhan, B. Rotational isomerism in N-(N-heteroaryl)arenesulphenamides. J. Chem. Soc. Perkin Trans. 2 1979, 1490-1495. [CrossRef] 
17. Atkinson, R.S.; Kelly, B.J.; Williams, J. Amination with 3-acetoxyaminoquinazolin-4-(3h)ones: Preparation of $\alpha$-aminoacid esters by reaction with silyl ketene acetals followed by $\mathrm{N} N$ bond cleavage. Tetrahedron 1992, 48, 7713-7730. [CrossRef]

18. Atkinson, R.S.; Barker, E.; Price, C.J.; Russell, D.R. The N-N bond as a chiral axis: 3-(diacylamino) quinazolin-4(3H)ones as chiral acylating agents. Chem. Commun. 1994, 1159-1160. [CrossRef]

19. Atkinson, R.S.; Barker, E.; Edwards, P.J.; Thomson, G.A. The N-N bond as a chiral axis: 3-diacylaminoquinazolinones as chiral acylating agents. J. Chem. Soc. Perkin Trans. 1 1996, 1047-1055. [CrossRef]

20. Al-Sehemi, A.G.; Atkinson, R.S.; Fawcett, J.; Russell, D.R. Stereoisomerism in 3-[N-(2-acetoxypropanoyl)$\mathrm{N}$-acylamino]quinazolin-4(3H)-ones, enantioselective acylating agents. J. Chem. Soc. Perkin Trans. 1 2000, 4413-4421. [CrossRef]

21. Arthur, R.J.; Coogan, M.P.; Casadesus, M.; Haigh, R.; Headspith, D.A.; Francesconi, M.G.; Laye, R.H. Stereostructural behaviour of N-N atropisomers: Two conglomerate crystallisations and a crystallisationinduced deracemisation. CrystEngComm 2009, 11, 610-619. [CrossRef]

22. Aitken, K.M.; Aitken, R.A.; Slawin, A.M.Z. The X-ray Structure of N-(Acetylamino)phthalimide, an Atypical Triacylhydrazine. J. Chem. Crystallogr. 2013, 44, 25-29. [CrossRef]

23. Iyer, A. Visible Light Mediated Photocatalysis of N-N Bond Based Compounds; North Dakota State Univeristy: Fargo, ND, USA, 2016.

24. Fletcher, J.R.; Sutherland, I.O. Conformational changes in hydrazine and hydroxylamine derivatives studied by nuclear magnetic resonance spectroscopy. Chem. Commun. 1970, 687-688. [CrossRef]

25. Verma, S.M.; Rao, S.O.; Sinha, K.O.P. Conformational analysis about N-N bond by NMR spectroscopy: $\mathrm{N}^{\prime}$-sulphyl derivatives of $\mathrm{N}$-aminoimides of anthracene-citraconic anhydride and naphthalene-maleic anhydride adducts. Bull. Chem. Soc. Jap. 1974, 47, 2311-2314. [CrossRef]

26. Verma, S.M.; Prasad, R. Conformational analysis by nuclear magnetic resonance spectroscopy. $\mathrm{N}^{\prime}$-derivatives of N-aminocamphorimides. J. Org. Chem. 1973, 38, 1004-1010. [CrossRef]

27. Verma, S.M.; Sinha, K.O.P.; Rao, C.K. Studies on N,N'-Diimidyl Systems by Nuclear Magnetic Resonance Spectroscopy. Can. J. Chem. 1974, 52, 2399-2402. [CrossRef]

28. Verma, S.M.; Singh, R.M. Assignment of Configurations to Adducts of 2-Substituted Anthracene with Maleic Anhydride by N.M.R spectroscopy. Aus. J. Chem. 1976, 29, 1215-1222. [CrossRef]

29. Verma, S.M.; Singh, M.D. Structural elucidation with nuclear magnetic resonance spectroscopy. Diels-Alder adducts of 1-aminoanthracene and maleic anhydride: Restricted rotation about the aryl C(1)-N bond and intrinsic asymmetry about the imide (Nsp2-Csp3) system. J. Org. Chem. 1977, 42, 3736-3740. [CrossRef]

30. Verma, S.M.; Prasad, R. Conformational analysis about the nitrogen -nitrogen bond by nuclear magnetic resonance spectroscopy. N'-Sulfonyl derivatives of N-aminocamphorimide. J. Org. Chem. 1973, 38, 3745-3749. [CrossRef]

31. Srivastava, A.; Samtani, S.; Verma, S.M. Role of Lone Electron Pairs of Heterocyclic Moiety in Controlling the Conformation about N-N Bond. Proc. Indian Natn. Sci. Acad. 1994, 60, 447-455.

32. Verma, S.M.; Singh, R.M. Structural Assignment by NMR analalysis of N-(Diacylamino)imide Derivatives. Diels-Alder Adducts of 2,3-Dimethylnaphthalene and 6,6-Diphethylfulvene with Maleic Anhydride. Bull. Chem. Soc. Jpn. 1978, 51, 516-519. [CrossRef]

33. Srivastava, V. Preparation and stereochemistry of some hydrazones derived from cyclic ketones. J. Sci. Res. 2011, 55, 111-117.

34. Trapp, O. Interconversion of stereochemically labile enantiomers (enantiomerization). Top. Curr. Chem. 2013, 341, 231-269.

35. D'Acquarica, I.; Gasparrini, F.; Pierini, M.; Villani, C.; Zappia, G. Dynamic HPLC on chiral stationary phases: A powerful tool for the investigation of stereomutation processes. J. Sep. Sci. 2006, 29, 1508-1516. [CrossRef]

36. Atkinson, R.S.; Judkins, B.D. Resolution of N-benzyl-N-(1,2-dihydro-2-oxoquinolin-1-yl)glycine. Tetrahedron Lett. 1979, 20, 4001-4002. [CrossRef]

37. Atkinson, R.S.; Edwards, P.J.; Thomson, G.A. Asymmetric induction mediated by an N-N chiral axis. Chem. Commun. 1992, 1256-1257. [CrossRef]

38. Al-Sehemi, A.G.; Atkinson, R.S.; Fawcett, J.; Russell, D.R. 3-Di-[(S)-2-acetoxypropanoyl]aminoquinazolin4(3H)-ones: Stereostructure and application in kinetic resolution of amines. Tetrahedron Lett. 2000, 41, 2243-2246. [CrossRef] 
39. Al-Sehemi, A.G.; Atkinson, R.S.; Fawcett, J.; Russell, D.R. 3-(N,N-Diacylamino)quinazolin-4(3H)-ones as enantioselective acylating agents for amines. Tetrahedron Lett. 2000, 41, 2239-2242. [CrossRef]

40. Al-Sehemi, A.G.; Atkinson, R.S.; Fawcett, J.; Russell, D.R. Kinetic resolution of amines by acylation using 3-diacylaminoquinazolin-4(3H)-ones. Chem. Commun. 2000, 43-44. [CrossRef]

41. Atkinson, R.S.; Draycott, R.D.; Hirst, D.J.; Parratt, M.J.; Raynham, T.M. Completely diastereoselective aziridination of $\alpha, \beta$-unsaturated acids via intramolecular reaction of 3-acetoxyaminoquinazolin-4(3H)-ones. Tetrahedron Lett. 2002, 43, 2083-2085. [CrossRef]

42. Kamiński, K.; Obniska, J. Design, synthesis, and anticonvulsant activity of N-phenylamino derivatives of 3,3-dialkyl-pyrrolidine-2,5-diones and hexahydro-isoindole-1,3-diones. Bioorg. Med. Chem. 2008, 16, 4921-4931. [CrossRef] [PubMed]

Sample Availability: Samples of the compounds are available from the authors as per federal and university protocols.

(C) 2019 by the authors. Licensee MDPI, Basel, Switzerland. This article is an open access article distributed under the terms and conditions of the Creative Commons Attribution (CC BY) license (http://creativecommons.org/licenses/by/4.0/). 